\title{
The Role of Collaboration in Collecting Relevant Feedback Keziah Doughty
}

\begin{abstract}
Improving library services for students and faculty relies heavily on clear communication and feedback from library users. I felt that Campion's "Library Services Survey" (a general survey covering broad aspects of the library) was an ineffective way of obtaining feedback - few patrons bothered to do the survey and it was difficult to pin-point problems or implement strategies to address them. By taking a more collaborative approach that involved library assistants, students of all year groups and faculty members, I was able to gather feedback and suggestions on a particular aspect of the library services, specifically the usefulness of a selection of online resources. Throughout this process, it was evident that collaboration had to be based on a genuine personal connection and a desire to provide the most beneficial online resources for both students and staff.
\end{abstract}

\section{Introduction}

As the Librarian and Study Skills Adviser at Campion College Australia, a liberal arts college in Sydney, I am responsible for managing a library collection of just over 25,000 physical books as well as a variety of ebooks, online journals and databases. These resources predominately cover the subjects taught at Campion including theology, philosophy, literature, history, Latin and Ancient Greek. Campion has around 100 students, most of whom are school leavers. This presentation is based on my experiences last year which highlights the importance of collaborating with students to collect relevant feedback about library resources. 


\section{Purpose for Collecting Feedback}

Improving and adapting library services and resources relies heavily on clear communication and feedback from library users. Campion includes a "Library Services Survey" among other surveys at the end of each semester, however, I was finding that few students actually completed this survey as it was quite long and the broad questions it contained were ineffective at identifying specific areas for improvement or demonstrating the usefulness of particular resources.

In 2016, I wanted to evaluate the usefulness of Campion's online resources and while the usage statistics provided some indication of how much each database or journal was being used, the statistics didn't really reveal the extent to which the content was helpful or useful for students, or if it was sufficiently accessible to them. The "Library Services Survey" likewise provided some indication of the level of satisfaction for online resources in general but was not specific to individual resources. Consequently, I decided that closer collaboration with students was needed to undertake a more thorough analysis of the usefulness of our online resources.

\section{Strategies}

In an effort to collaborate with the students to gather effective feedback, I utilised a few different approaches. Firstly, I created small feedback slips which asked users if they had found what they were looking for, if there was a subject area they wanted more resources for and what type of format they preferred using (book, journal, online journal, online database for example). This feedback generally came from students using the library's front desk services and provided some insight into their preferences regarding subject and format.

As the students seemed quite happy to provide this feedback, I decided to try some informal focus groups to gauge their opinions on the online resources. To do this, I simply approached the students, asked about their studies or a particular assignment and then asked if they would mind sharing what they thought of the online resources with me for a moment or two. I targeted students from all year groups, including those who tended not to borrow physical books or use the front desk services. While this was very informal (I didn't take any notes while I was with them) it was also highly insightful as the students really opened up and started to talk freely about what they enjoyed or found difficult concerning the online resources when I made it apparent that I was genuinely interested in what they thought. This informal method also allowed me to ask some follow-up questions to clarify comments and explore not just what resources students enjoyed using, but also whythey found them helpful. 


\section{Online Survey}

To make changes to library services and resources, especially changes that involve the budget, more concrete results are needed. As a more official method of collecting feedback, I designed and sent an online survey to all the students. This was the first time that I had used this method or written a survey for such a specific aspect. I used the information I had received from the feedback slips and focus groups to narrow the range of the survey and I enlisted the help of my student library assistants to help formulate it and provide suggestions on the wording and format. The assistants also helped me test the survey before I sent it to the entire student body.

As students are often asked to complete fairly long surveys, I kept this one short to mitigate the effect of 'survey fatigue'. As a result, the survey had 10 questions, only 8 of which were compulsory. The first question in the survey was "How well do you feel you use the library's online resources?" Students could then evaluate their own research practises by choosing an answer from 'Efficiently' to 'Could do better.' I also ensured that there was an option to select 'I don't use the online resources' to capture any data from these students. A number of the following questions provided a scale for students to rate the usefulness of specific resources (from 'very useful' to 'not useful' and 'what's this?'). One of the questions was used to determine the value that students placed on these resources by asking them "Overall, how important are online resources to you?" I also provided a comment field for all of the questions to allow students the opportunity to provide additional comments should they wish to do so.

I was aware that surveys tend to be very dry and repetitive with formal language so I made an effort to use humour and more casual language to engage the students and make them a little more interested in responding. I really tried to emphasise in both the email I sent asking the students to complete the survey and in the survey its self the fact that their collaboration and honest feedback was very important as it would help the library provide the best resources for their needs.

Finally, I provided some external motivation by allowing all students who completed the survey to choose a book (for free) from those that were left over from a recent book sale. This was done purely on a trust basis and was also a way of thanking the students for their collaboration in this project.

\section{Results}

I was very happy with the results from the survey as over half the student population completed it. Many of the students also provided additional comments and ideas in the optional comment field that I provided which were very helpful in analysing the results. A few key issues were identified including some resources that were not so beneficial to students, difficulties with access, and the need for continuing education on using the resources and reminding students about them. After some discussion with the faculty, I developed some strategies to deal with these. 


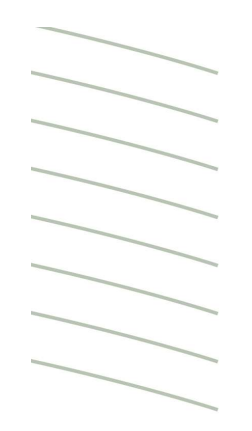

\section{Outcomes}

As a result, a couple of online resources were discontinued and the ones that were retained were promoted more heavily. I also worked on better ways of making the online resources more visible in the catalogue and accessible for students. To date, I have not received any complaints about the cancelation of online resources and the ones that were retained have seen a massive spike in usage and downloads.

I have tried to provide more educational workshops on using the online resources throughout the semester, as opposed to just during the first few weeks, and produced a small booklet (Choosing and Using Online Resources) to help students with this. More information has been provided on the website and I also increased communication, both written and verbal, with the students to remind them of the resources and how to access them. This year I have had far less inquiries about what online resources we have or how to access them.

More importantly however, students have commented to me that they are happy with the online resources that the library provides and the faculty have reported to me that students are using valuable online resources and demonstrating relevant research in their written work and assignments.

Throughout the process of seeking to obtain feedback from students, I tried to make it clear in all communication and interaction with them that I wanted to provide the best possible materials for them. When they realised that the feedback slips, focus groups and survey were offering them a chance to collaborate in this entire process, the students were willing to honestly share their opinions, experiences and ideas. Overall, this was a valuable process not just for me but also the students, the library and the college community.

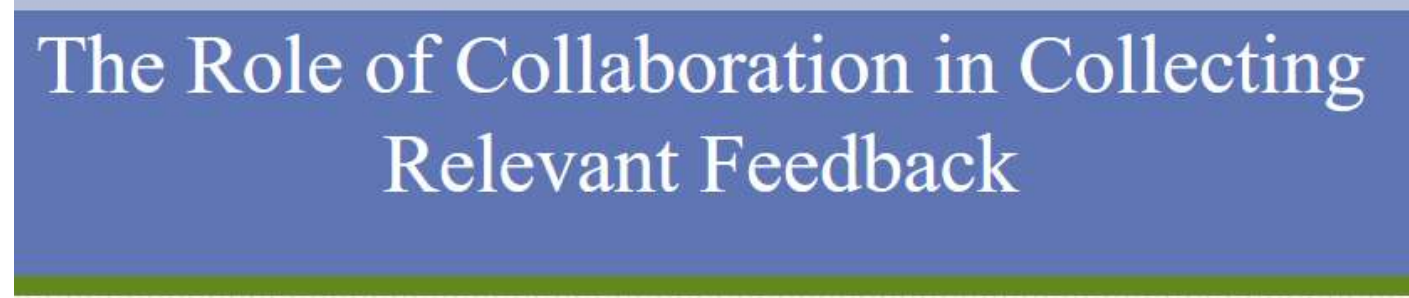

Keziah Doughty,

ANZTLA Conference, July 2017 


\section{Purpose}

- Need to evaluate the usefulness of online resources.

- General 'Library Services Survey' insufficient:

- Too lengthy,

- Impersonal language,

- Broad questions not relevant to evaluation of specific resources.

- Usage statistics are helpful; also need student feedback.

\section{Strategies}

- Feedback slips

- Three simple questions relating to subject and format.

- Informal focus groups

- General feedback on online resources.

- Online survey

- Targeted to specific resources.

\section{Online Survey}

- Short with a narrow focus.

- Most questions had an optional comment box.

- Humour was important!

- The value of collaboration was emphasised.

- External motivations/rewards provided. 


\section{Results}

- High response rate.

- Key issues identified:

- Less beneficial resources,

- Access problems,

- Continuing education.

- Strategies developed and implemented with discussion and support from the faculty.

\section{Outcomes}

- Some resources discontinued; others promoted.

- More instructional workshops.

- Educational booklet and information on website.

- More frequent communication.

- Student and faculty satisfaction. 